THE ANNALS OF "DUNĂREA DE JOS" UNIVERSITY OF GALATI

FASCICLE III, 2020, VOL. 43, NO. 1, ISSN 2344-4738, ISSN-L 1221-454X

ELECTROTECHNICS, ELECTRONICS, AUTOMATIC CONTROL, INFORMATICS

Article DOI: https://doi.org/10.35219/eeaci.2020.1.06

\title{
CHOOSING THE MAIN ELEMENTS OF AN ACTIVE POWER FILTER WITH FAP-TOOL APPLICATION
}

\author{
Alexandru Dușa*1 ${ }^{1}$, Ciprian Daniel Bălănuță ${ }^{1}$, Gelu Gurguiatu ${ }^{1}$, Constantin \\ Drogeanu ${ }^{2}$ \\ 1 ,'Dunărea de Jos" University of Galați, Romania \\ ${ }^{2}$ Uniel Serv \\ *Corresponding author: e-mail: alexandru.dusa@ugal.ro
}

\begin{abstract}
This paper presents the electronic application FAP-tool, which includes the following applications: P-tool, C-tool, M-tool and Daq-tool developed within the project "Knowledge Transfer Regarding the Energy Efficiency Increase and Intelligent Power Systems" (acronym CRESC-INTEL). The FAP-tool application allows the user as the technicians and/or engineers to introduce the data from the analyzed electrical system where is necessary to connect the Active Power Filter. With the FAP-tool application they get recommendations on the following aspects: topology of the Active Power Filter that can be used, the control method that provides the best results, the values of the passive elements to ensure the connection to the grid and the appropriate control board. All those data are returned as a list of the components which may be used.
\end{abstract}

Keywords: energy efficiency, power quality, active power filter, electronic application.

\section{INTRODUCTION}

Power quality is a very important objective in the electric power system. Maintaining the quality of electricity within the standards has lately been more complicated, due to the technological developments that have diversified the types of electricity consumers. Most of these consumers are nonlinear, generate harmonics, create unbalances, and consume reactive power.

To reduce the problems caused by nonlinear loads, the Active Power Filter is the most suitable equipment to be used. They are voltage and controlled sources which allow the compensation of all deficiencies that may arise in the electrical grid.
From the point of view of the power circuit configuration, the active filters are divided as follows (Gurguiatu, 2016):

- Series Active Filters;

- Parallel Active Filters;

- Hybrid Active Filters.

The use of one of these topologies depends on the nature of the problems in the electrical system.

The control of active power filters is performed with several command methods encountered in the literature (Bălănuță, 2012): 
- The control method developed on the basis of the instantaneous powers principle (PQ);

- The control method developed on the basis of the synchronous algorithm principle (DQ);

- The control method developed based on the indirect control principle;

- The control method developed on the basis of the current synchronization principle with the positive voltage sequence component:

- The control method developed on the basis of the band-stop Filter principle (BSF);

- The control method developed on the basis of the low-pass Filter principle (LPF);

- The control method developed on the principle of maximum.

Each of these control methods is distinct in its own way, with impressive results in case of correct choice of the control strategy for compensation (Bălănuță, 2012).

Choosing the right topology and the control method for sizing the Active Power Filter that can provide the best results has always been a challenging issue.

Due to the project "Knowledge Transfer Regarding the Energy Efficiency Increase and Intelligent Power Systems" (acronym CRESC-INTEL) which aims to increase the transfer of technological knowledge and personnel between "Dunărea de Jos" University of Galati and businesses companies in the field of electricity, to increase the energy efficiency by intelligent power systems, in order to obtain a competitive, technical and economical solution for an intelligent system of the Active Power Filter, it was possible to implement the FAP-tool application, that allows the optimal determination of the topology based on the applications previously developed in this project: P-tool, C-tool, M-tool and Daq-tool.

The C-tool application - is capable to indicate the right elements available for the construction of the $\mathrm{L}$, LC and LCL filters, included in the APFs structure (Bălănuță, et al., 2019). The P-tool application - is capable to recommend the APF topology to use in specific, user defined, conditions (Gurguiatu, et al., 2018). The M-tool application - is capable to indicate the most appropriated control strategy in certain conditions (Gurguiatu, et al., 2019). The Daq-tool application - is capable to assist designers in selecting the appropriate control system for the APF, starting from a set of specific requirements (Bălănuță, et al., 2019).

\section{SIZING THE PASSIVE ELEMENTS OF THE ACTIVE POWER FILTER}

This chapter presents the calculus formulas for sizing the passive elements required in the construction of the passive filter used to connect the Active Power Filter to the grid.

\subsection{L type filter}

The calculus of the filter $L_{F A}$ is determined in (Moran, et al., 1995) based on the fact that for a given frequency, the slope of the current through the active power filter - $i_{F A}$ must be lower than that of the triangular carrier signal, which characterizes the switching frequency. The slope of the carrier signal is determined by:

$$
\text { (1) } \chi=4 \cdot \varepsilon \cdot f_{s}
$$

where $\varepsilon$ represents the amplitude of the triangular signal and $f_{s}$ - switching frequency.

The maximum current slope $i_{F A}$, for the active filter is characterized by:

$$
\text { (2) } \frac{d i_{F A}}{d t}=\frac{0.5 \cdot U_{c c}+U_{s m}}{L_{F A}}
$$

where

$$
\text { (3) } \quad L_{F A}=\frac{0.5 \cdot U_{c c}+U_{s m}}{4 \cdot \varepsilon \cdot f_{s}}
$$

In equation (3) $U_{c c}$ is the voltage from the DC line and $U_{s m}$ - the maximum value of the power supply voltage.

\subsection{L-C filter}

To define the $L-C$ filter it is necessary to determine the value of the $L$ filter given by (3) and to calculate the filtering capacity using (4).

$$
\text { (4) } C=\frac{1}{\left(2 \cdot \pi \cdot f_{c}\right)^{2} \cdot L}
$$

\subsection{L-C-L filter}

The size of the $L-C-L$ filter is achieved by: calculation of the inductance $L_{F A}(3)$, calculation of the filtering capacity $C(4)$ and calculation of the value of the resistance related to the filter (6) (Hojabri \& Hojabri, 2015) (Tavakoli Bina \& Pashajavid, 2009):

(5) $\quad L_{1}=(4 \div 6) L_{2}$ 
(6) $\quad R_{d}=3 \cdot \frac{1}{2 \pi f_{r e f} C}$

Taking into account that the highest range of the compensating harmonics is 40 and applying a constant of 1.25 to $f c_{\max }$, a minimum limit of $2.5 \mathrm{kHz}$ and a maximum of $3 \mathrm{kHz}$ result for the resonant frequency. At the same time, if the total inductance $L_{d}=4.5 \mathrm{mH}$ and $f_{\text {res }}$ is dependent on $k$ and $C$, the following constraints will result (Tavakoli Bina \& Pashajavid, 2009):

$$
\left\{\begin{array}{c}
2500 \leq f_{\text {res }} \leq 3000 \\
f_{\text {res }}=\frac{1}{2 \cdot \pi} \cdot \frac{(k+1)}{\sqrt{0.0045} \cdot \sqrt{k \cdot C}}=2.37 \frac{(k+1)}{\sqrt{k \cdot C}}
\end{array}\right.
$$

\section{FAP-TOOL APPLICATION}

Within the project "Knowledge Transfer Regarding the Energy Efficiency Increase and Intelligent Power Systems" (acronym CRESC-INTEL) an electronic application called the FAP-tool has been developed. The main objective of this application is to allow qualified and unqualified persons to determine quickly the most efficient topology and control methods for an Active Power Filter, to calculate the passive elements that are components of the filter, to choose the passive elements and the acquisition systems that match from the lists proposed by the application.

\subsection{FAP-tool}

Figure 1 shows the main window of the FAP-tool electronic application, in which the data from the analyzed electrical system are introduced by selecting the type of electrical distribution system to which the Active Power Filter is to be connected. Also, in this page the type of Active Power Filter which is to be implemented is selected introducing the data about the Active Power Filter.

The data corresponding to the measured electrical parameters are introduced into the yellow cells to be easily recognized by the user. In the presented example the input data are:

- Nominal electrical power: S (kVA): $200-$ represents the nominal power of the nonlinear load;

- Nominal voltage: U (V) 400 - represents the grid voltage in CCP (Common coupling point);

- Nominal frequency: f $(\mathrm{Hz}) 50$ - represents the nominal frequency of the electrical grid;

- Power factor: $\mathrm{k}_{\mathrm{p}} 0.82$ - represents the power factor of the non-linear load in the CCP.
- Current unbalance: $I_{\text {unb }}(\%) 20$ - represents the current unbalance, due to the non-linear load;

- Voltage unbalance: $\mathrm{V}_{\text {unb }}(\%) 1$ - represents the measured voltage unbalance, due to the nonlinear load;

- Total Demand Distortion (current): TDD (\%) 20 - represents the harmonic level on the measured current, due to non-linear load;

- Total Harmonic Distortion (voltage): THD (\%) 6 - represents the harmonic level on the measured voltage, due to non-linear load;

- Flicker: PLT(\%) 0.1 - represents the measured flickers.

APF data:

- Switching frequency: $\mathrm{f}_{\mathrm{sw}}(\mathrm{kHz})-15$;

- $\quad$ Limit to minimum voltage: $\Delta \mathrm{U}_{\mathrm{Cmin}}(\%)-10$;

- Voltage drop allowed: $\Delta \mathrm{U}_{\mathrm{C}}(\%)-5$;

- The number of cycles of the conduction processes: $n_{c}-6$;

- Resonant frequency of the passive filter: $\mathrm{f}_{\mathrm{c}}(\mathrm{Hz})-2500$.

\begin{tabular}{|c|c|c|c|}
\hline \multicolumn{4}{|c|}{ 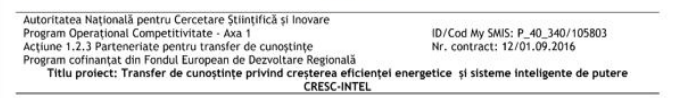 } \\
\hline \multicolumn{4}{|c|}{ Input values } \\
\hline System type & \multicolumn{2}{|l|}{ Monotazat } & $\nabla$ \\
\hline Nominal electrical power & s & 200 & kVA \\
\hline Nominal voltage & $u$ & 400 & $\mathrm{v}$ \\
\hline Nominal frequency & $f$ & 50 & $\mathrm{~Hz}$ \\
\hline Power factor & $k_{p}$ & 0.82 & \\
\hline Current unbalance & lunb & 20 & $\%$ \\
\hline Voltage unbalance & $V_{\text {unb }}$ & 1 & $\%$ \\
\hline Total Demand Distortion (current) & TDD & 20 & $\%$ \\
\hline Total Harmonic Distortion (voltage) & THD & 6 & $\%$ \\
\hline Fliker & PLT & 0.1 & $\%$ \\
\hline \multicolumn{4}{|c|}{ Calculated values } \\
\hline ACTIVE current & $I_{1 p}$ & 190.2 & A \\
\hline REACTIV current & $I_{10}$ & 132.7 & $\mathrm{~A}$ \\
\hline DISTORTING current & $I_{D}$ & 47.3 & A \\
\hline TOTAL current & Itotal & 236.7 & $\mathrm{~A}$ \\
\hline Injected current of the APF & $I_{F}$ & 140.9 & $A$ \\
\hline \multicolumn{4}{|c|}{ APF Data } \\
\hline Active filter type & \multicolumn{2}{|l|}{ Trifazat 3 brate } & $\nabla$ \\
\hline Switching frequency & $f_{5 w}$ & 15 & $\mathrm{kHz}$ \\
\hline Limit to minimum voltage & $\Delta U_{\text {cmin }}$ & 10 & $\%$ \\
\hline Voltage drop allowed & $\Delta U_{c}$ & 5 & $\%$ \\
\hline The number of cycles of the conduction processes & $n_{c}$ & 6 & \\
\hline Resonant frequency of the passive filter & fc & 2500 & $\mathrm{~Hz}$ \\
\hline Duration of a charging cycle & $\mathrm{t}_{\mathrm{c}}$ & 0.0033 & 5 \\
\hline Voltage imposed on the capacitor & $u_{c}$ & 762.10 & $\mathrm{v}$ \\
\hline
\end{tabular}

Fig.1. FAP-tool application interface 
Fig. 2 presents the second main window of the electronic application FAP-tool, where a series of results is briefly presented, called "Minimum results obtained" which can be classified into four categories:

- Recommended filter topology, where information about the type of Active Power Filter that can be used is presented;

- Recommended control method - here is the information about the control method which shows the best results for minimizing electricity quality problems;

- Connection and storage elements - the calculated values of the passive elements required for the construction of the filter are presented;

- The control panels show the number of input and output signals.

In our case the recommendations made by the FAPtool are the following:

- Recommended filter topology: Shunt;

- Recommended command method:Sec_Poz.
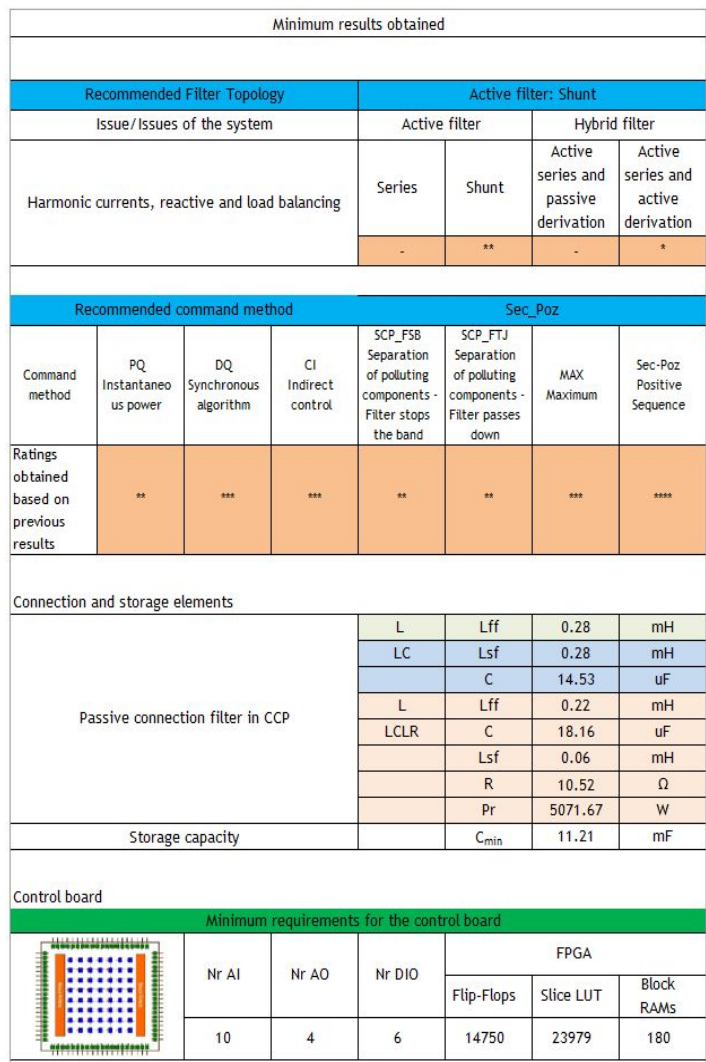

Fig.2. FAP-tool application interface
After introducing the input data the FAP-tool application allows to the user to obtain a wide report, being composed of the following subcategories:

- General information;

- Recommended active/hybrid filter topology information;

- Grid connection information and energy storage capacity;

- Information about the ordering method;

- Control board information.

\subsection{Report}

This subsection presents information about the input data (introduced by the user and the calculated ones), as well as the results obtained in general, based on the input data.

In Fig. 3 the data introduced by the user is presented in the first window, as well as those about the currents circulating through the system. Finally these are calculated values.

\begin{tabular}{|l|c|c|c|}
\hline & \\
\hline
\end{tabular}

Fig.3. The first page of the Report window

Fig.4 presents the information about the recommended active filter topology which can be 
THE ANNALS OF "DUNĂREA DE JOS" UNIVERSITY OF GALATI

FASCICLE III, 2020, VOL. 43, NO. 1, ISSN 2344-4738, ISSN-L 1221-454X

used in the electrical system described by the input variables. In addition, a list of possible static power devices is provided.

Fig.5 presents the connection types of passive elements that can be used to connect the Active Power Filter to the system, as well as the calculated values of these elements. There are three types of filtration: $L, L-C$ and $L-C-L$. Thus, the user can choose to implement one type of passive connection filter out of the three available, depending on the nature of the application.

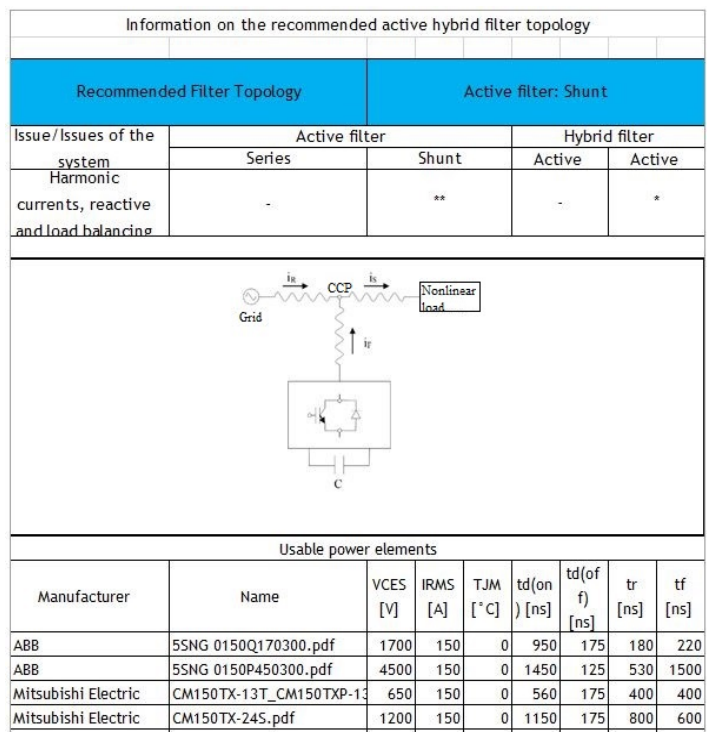

Fig.4. Page two of the Report window

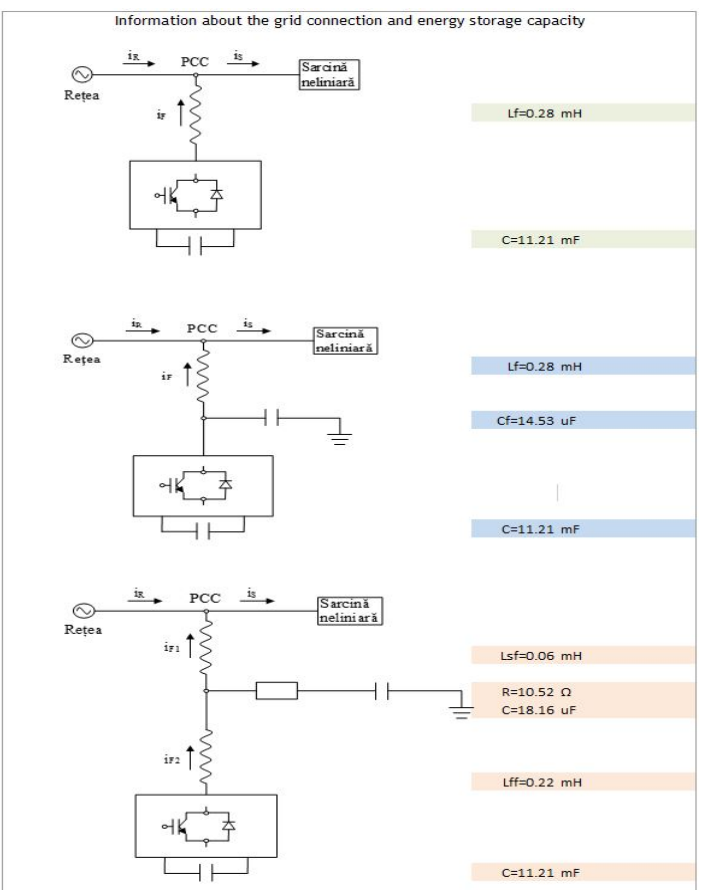

Fig.5. Page three of the Report window

Fig.6 presents the fourth page of the Report. It contains a list of passive components, made by various manufacturers which can be used in equipping the Active Power Filter for the connection to the network or for storing the energy needed to the filter. The values of the passive components are determined in Fig. 5.

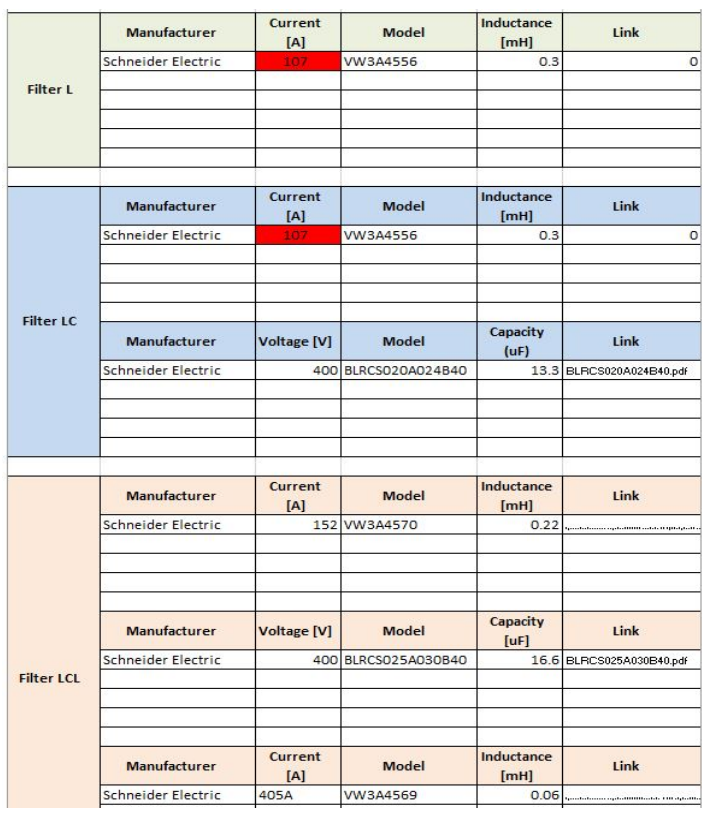

Fig.6. Page four of the Report window 
The control method which can deliver the best results for the electrical system that is defined by the input values is presented in Fig.7.

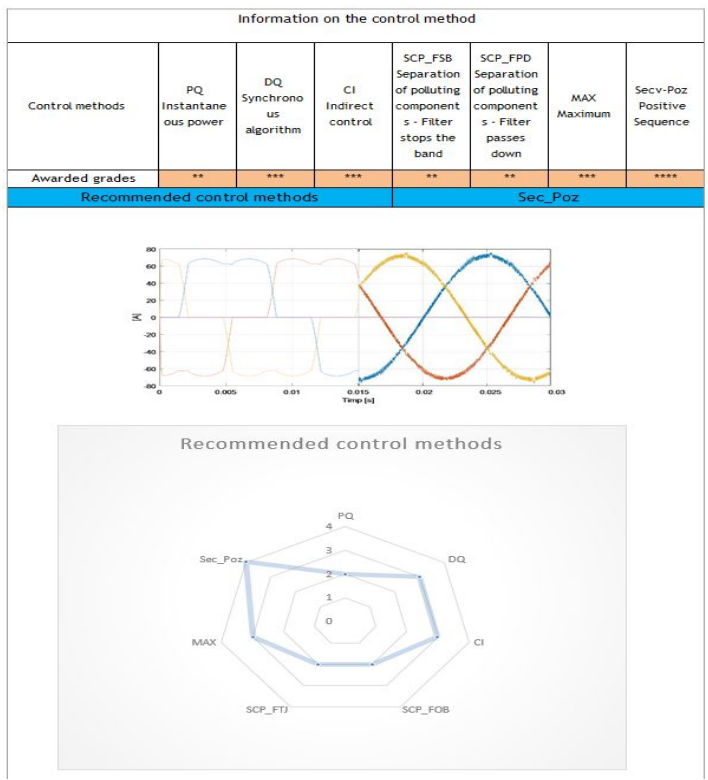

Fig.7. Page five of the Report window

It is in a graphical form in which the results obtained by the other types of control methods are presented. Thereby, the user knows that there are more control methods for solving the issue, but the control method with the most stars is the best solution

Fig. 8 presents the block diagram of the control method recommended by the electronic application FAP-tool.

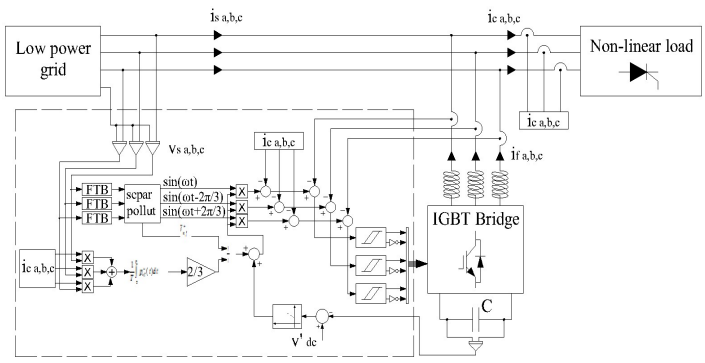

Fig.8. Page six of the Report window

In Fig.9 is presented the block diagram of the electrical system where the Active Power Filters are connected. Also here is provided to the user the list of acquisition boards that can be used to make the Active Power Filter.

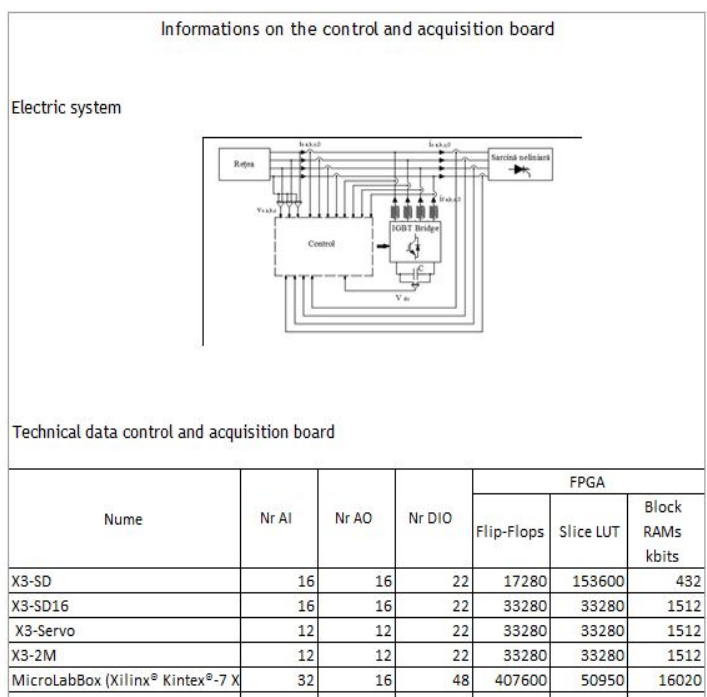

Fig.9. Page seven of the Report window

After all the input data is introduced into the FAPtool application, the obtained results will provide the suggestions regarding these four aspects: power elements, passive elements, control strategy, control board in a report.

\section{ACKNOWLEDGMENT}

This study was supported by the CRESC INTEL project Knowledge Transfer Regarding the Energy Efficiency Increase and Intelligent Power Systems", code SMIS 105803, project co-funded by the European Union from the European Regional Development Fund through the Competitiveness Operational Program 2014-2020.

\section{CONCLUSION}

In this paper, the electronic application FAP-tool was briefly presented. This application comes to support the people who want to design Active Power Filters. Finally it offers the calculus and selection of the components related to the Active Power Filter in the database.

\section{REFERENCES}

Bălănuță, C. D., 2012. Cercetări și contribuții privind îmbunătățirea calității energiei electrice în sistemele electrice. Galați, s.n. Doctoral thesis.

Hojabri, M. \& Hojabri, M., 2015. Design, application and comparison of passive filters for threephase grid-connected renewable energy systems. ARPN Journal of Engineering and Applied Sciences, 10(22), pp. 10691 - 10697.

Moran, L. A., Dixon, J. \& Wallace, R. R., 1995. A three-phase active power filter operating with fixed switching frequency for reactive power 
and current harmonic compensation. IEEE Trans. Ind. Electron, 42(4), pp. 402 - 408.

Tavakoli Bina, M. \& Pashajavid, E., 2009. An efficient procedure to design passive LCLfilters for active power filters. Electric Power Systems Research 79, pp. 606 - 607.

Gurguiatu, G., Bălănuță, C. D., Dușa, A., Roșu, E. M., Munteanu, T., 2018. P-TOOL - A software application for choosing the topology for active power filters. The annals of "Dunarea de Jos" University of Galati, 41(2), pp. $31-38$.

Bălănuță, C. D., Gurguiatu, G., Dușa, A., Voncilă, I., Puiu, C., Necula, D., 2019. Choosing the control and data acquisition system using DAQtool application. The Annals of "Dunarea de Jos" University of Galati, 42(2).

Bălănuță, C. D., Gurguiatu, G., Dușa, A., Roșu, E. M., Voncilă, I., Drogeanu, C., 2019. L, LC and LCL filter choosing by C-tool application. The annals of "Dunarea de Jos" University of Galati, 42(2), pp. 10 - 14.

Gurguiatu, G., Bălănuță, C. D., Dușa, A., Roșu, E. M., Voncilă, I., Dumitrescu, M., Anton, A., 2019. Active power filter control strategy choosing by M-tool application. The $6^{\text {th }}$ International Symposium on Electrical and Electronics Engineering, 978-1-7281-29068/19/\$31.00 (2019 IEEE.

http://www.ni.com/ro-ro.html

https://www.dspace.com/en/pub/home/products.cfm

https://www.entegra.co.uk

https://www.opal-rt.com/fpga-and-i-o-expansion-box 